\title{
Providing Physical Fitness and Wellness for the School Children through School Health Programme
}

\author{
Ajayi-Vincent, O.B (PhD). \\ Ekiti State University, Ado - Ekiti. Dept. of Human Kinetics \& Health Education.
}

\begin{abstract}
Today, inactivity and unhealthy lifestyle habits have eaten deep into the fabric of modern man's life posing serious threat to good health. To address this trend requires urgency in looking for means by which the awareness of man could be re-awaken towards ways by which an individual can be equipped with knowledge to improve his health by taking actions that guarantee better and healthier life. This paper therefore discussed physical fitness, wellness and their components in relation to how they could be provided for, through a well planned and implemented school health education programme for the school children to combat inactivity and negative lifestyle habits. It was concluded that a well planned, organized and funded school health programme can provide for physical fitness and wellness programme in the school system.
\end{abstract}

\section{Introduction}

The importance of good health to human life is very immense when the kind of life to be enjoyed and productivity to various phases of human endeavour are quantified. The concept of good health has gone beyond the idea of completeness of state and absence of illness or not being sick in bed. Nations have embraced the notion of health as a state of positive and total well-being involving all the dimensions/components of health (physical, mental, social, emotional, spiritual etc.) (Hoeger and Hoeger, 1996). According to Ajayi- Vincent and Adesina (2008) quoting Hahn and Payne 1999, it is the ability to access and apply resources from the various dimensions of health to the experiences of daily living, thus assuring growth and development and the sense of well-being that it affords. A state of well-being that guarantees individuals optimum efficiency both at work, play and to life in the society.

Physical fitness and wellness are two terms that are usually used interchangeably to express good health. The two are good pointers to what good health stands for but it is worthy of note that they are not synonymous in the real sense of it. One is a component of the other, fitness is the ability to persevere on a task where an unfit persons fail. It is a component of wellness which implies a constant and deliberate effort to stay healthy and achieve the highest potential for well being.

Good health however, is a highly valued asset in any sane society, possession of which is crucial if an individual wishes to get the greatest possible satisfaction from life and make his fullest contributions to it. This is the essence of school health education in the school system. Health education in the school system is an outgrowth of the universal search for more effective and more enjoyable living (Adegboyega, Ajayi-Vincent and Adesina, 2005). It was realized that school as an agent of cultural transfer and change can also prepare a person to do what is necessary for the protection, preservation and promotion of his health. Saddled with these responsibilities, it becomes imperative for the school to administer the school health education programmes leading to the achievement of these goals effectively.

It is therefore the focus of this paper to discuss physical fitness and wellness in relation to the life of the school children and life in our society and the way by which they can be provided for through administration of a good and functional school health programme.

\section{What is Physical Fitness?}

The ability of an individual to adapt and respond favourably to physical efforts could be seen as physical fitness. It is the degree to which an individual is able to function effectively or live a full and balanced life. In the words of Hockey (1993), physical fitness is the ability to carry out daily tasks with vigour and alertness, without undue fatigue and with ample reserved energy to enjoy leisure time pursuits and to meet unforeseen circumstances and emergencies. According to Hoeger and Hoeger (1996), this implies that individuals are physically fit when they can meet both the ordinary and unusual demands of daily life safely and effectively without being overtly fatigued and still have energy left for leisure and recreational activities. Maintaining a high level of physical fitness generally should be an aspiration for all, because of its immense contribution to healthy and meaningful life (Nwankwo and Salawu 1995).

Physical fitness as a construct can be classified into two namely, health-related and motor performancerelated fitness components. The main interest of this paper is in the health-related fitness components, although the performance-related components are of immense benefits when competitive sports are involved. The health- 
Providing Physical Fitness and Wellness for the School Children through School Health Programme

related fitness components are appropriate body build and composition, muscular strength, muscular endurance, musculoskeletal flexibility and cardio-respiratory endurance. In the words of Ajayi-Vincent and Adesina (2008), optimal level of development in these components is crucial for adequate growth, development and well-being. As it has been stated earlier, the motor performance-related components of fitness are of significant importance for successful feat in competitive sporting events and in lifetime sport and pursuits. Prominent among these motor performance-related fitness components are, agility, power, speed, reaction time, coordination and balance. It is worth mentioning also that good motor performance related fitness components also enhance overall quality of life by helping people cope more adequately in emergency conditions. Both the health-related and motor performance-related fitness components should be recognized and adequately provided for in the school health education programme to enhance a robust health of the school children.

Meaning of Wellness and its Components Wellness is the new emerging concept used to describe good health. It emerged in response to the quest for an appropriate word to describe good health after it has been discovered that improving physical fitness component alone was not enough in any way to lower the risk for diseases and ensure better health. According to Hoeger and Hoeger (1996), good health is no longer viewed as simply the absence of illness. They further stated that the notion of good health evolved notably in the last few years and continue to change as scientists learn more about lifestyle factors that brings in illness and affect wellness. In the opinion of Merki and Merki (1987), wellness considers health in broad terms and it is a way of living each day that includes choices and decisions based on healthy attitudes. Wellness as a concept portrays health as dynamic rather than passive because it is constantly changing.

In the words of Hoeger and Hoeger (1996), wellness is defined as the constant and deliberate efforts to stay healthy and achieve the highest potential for well-being. In other words, a person needs to give him/herself to a lifestyle that will lead to positive outcomes in the seven dimensions of health. Broadly speaking wellness incorporates the following components namely, physical fitness, healthy nutrition, disease prevention, appropriate and adequate health education, spirituality, stress management and smoking cessation. Others are personal safety, social support, medical/physical examinations, substance control, self worth, cardiovascular risk reduction and environmental support. The implication of this is that for one to live a wellness way of life, such an individual must be physically fit and manifest no signs of disease and must not have risk factors for diseases. Programmes to cater for all these components of wellness must be provided for in the school health education programme to improve the health and quality of life of the school children.

\section{Benefits of Physical Fitness and Wellness Programmes}

Regular participation in adequate doses of physical fitness and wellness programmes has great benefits to man. The greatest benefit is that physically fit individuals live life to its fullest potential and have fewer health problems than inactive individuals who also may indulge in negative lifestyle pattern. Regular and adequate doses of physical fitness programme will improve and strengthen the various systems of the body. Notable among these systems are the circulo-respitatory, muscular, skeletal, nervous and digestive systems. Also it improves body posture and physical appearance and helps to maintain appropriate body build and composition. Ogwu (1995) expressed the view that regular exercise reduces anxiety, emotional outburst and develops high tolerance levels. Adequate doses of exercise and wellness lifestyle also sharpen the social values and habits of individuals.

Provision of Physical fitness and wellness programme through school health Programme.

The school health programme involves many activities as it concerns with many people of different professions. It comprises all health activities, which are planned, organized and carried out under the auspices of the school. Udoh (1980) according to Ogundele (2002) perceived school health programme as primarily concerned with developing an understanding of health and providing necessary experiences and services which play a key role in the maintenance and improvement of the school of both pupils and school personnel. While the programme seeks to maintain and promote the health of the school child, it extends such services to the teachers and other workers in the school. As the teachers and other workers need protection from communicable diseases that could be spread by the school children, so also the children need protection from those diseases that could be spread by the staff in the school.

The activities of the school health programme can be expressed under the phases of the programme. Traditionally there are three interdependent phases of the school health education programme namely, the school health instruction, school health services and the healthful school living. These are the programmes under which the physical fitness and wellness programmes can find expression to impart on the school children. The school health instruction according to Ogundele (2002) is the aspect of school health education programme which is concerned with the process of planning and organization of learning experiences for the learner under the guidance, supervision or direction of the class teacher or accredited health personnel (e.g. physician or nurse). It is the organized teaching procedures directed towards developing understanding, attitudes and practices relating to health and factors affecting health. It is the phase of the school health education programme 
where scientific information are disseminated to the school children as well as methods of applying the acquired information.

This phase provides a veritable ground for dissemination of information that bother on physical fitness and wellness programme. The only way for any school to achieve this is to design and encourage a well structured school health instruction programme, with adequate class periods allotted for regular instructions by qualified personnel on issues such as drugs, sexuality, nutrition, physical fitness, rest, stress management, sanitation, safety and a host of other related subjects. If this is done, it becomes possible to inculcate in the school children a regular habit of exercise consciousness and various strategies and principles for behavior modification right from their formative stage of life to influence their adult wellness life style. According to Hoeger and Hoeger (1996), the incidence of killers diseases has decline in United State America (USA) because people are now more aware of the risk factors for all the diseases and are changing their lifestyle to lower their potential risk factor for the diseases through health education (instruction).

The school health services is the second phase of the school health education programme. It is very important and the implementation consists of many phases attracting many personnel with specific expertise. According to Udoh, Fawole, Ajala, Okafor and Nwana (1987), this phase constitutes those school activities directly concerned with the present and existing health status of the school children. It also reflects sound public health and educational principles.

This phase refers to the cooperative activities of the school teachers, physicians, dentists, nurses, counselors and others for the purpose of appraising, promoting and maintaining the health of all the school children and personnel. It provides an umbrella for all the procedures established to appraise the health status of students, school personnel, counsel students, parents and others concerning appraisal findings and to prevent and correct physical and remediable defects.

This phase is sub-divided into two, appraisal and preventive phases. The appraisal phase deals with an evaluation or assessment of the present health status of a person. It deals with the relationship of a person health attainment to the basic endowment and his adjustment to life needs. Both physical fitness and wellness programmes can also be provided for under this phase. The physical fitness components of the school children can easily be assessed through the use of appropriate assessment procedures.

As it has been stated earlier, physical fitness is a construct and no single test can provide a complete measure of it. For example the health related fitness has five different components-cardio-respiratory endurance, muscular strength, muscular endurance, musculoskeletal flexibility and appropriate body build and composition. Each of these components has a number of measuring instruments and out of these, selections are made to package a battery of tests to determine an individuals overall level of fitness. Health appraisal also include physical and medical health examinations, dental examination, physical observation, screening tests for visual and auditory acuity and taking of health history of the children. Through all these tests, physical impairment can be detected and referral made.

The preventive aspect of the school health services deals with issues of communicable and noncommunication diseases, safety promotion, first aid and emergency care, substance abuse control and spirituality etc. Major health problems which can have negative influence on the wellness status of the school children are identified and necessary preventive measures sorted out and applied. The fact that children come from various homes is incontestable, they bring with them a lot of health problems which may include any of the identified communicable diseases. It is necessary to stem up certain preventive measures to guard and protect the health of the healthy ones while the sick is not ignored or neglected while in school. Some of these measures include provision of healthy environment, isolation of student, immunization, re-admitting the sick student back to school etc.

On the issue of first aid and emergency care, by law, the school acts in loco-parentis for the school children. It is therefore assumed that the child will receive the same care and protection during school hours as he/she would receive at home. There could be sudden illness or injury to the children, the school should see to the immediate care through qualified personnel, facilities and supplies.

The third phase of the school health programme is the school healthful living. According to Ogundele(2002), the phase encompasses all the various physical, emotional and social aspects of the school and the measures provided at the school to ensure healthy environment for the school children. This phase is also sub-divided into two, namely the physical aspect and the emotional/social aspect. The physical aspect has to do with the provision of physical infrastructure and facilities to effect the successful implementation of the first two phases of the programme. Adequate provision of buildings for classrooms, administrative offices, laboratories, health bays etc. with good ventilation and lighting is very crucial to this phase. Likewise, provision of facilities for toilet and waste disposal, food services, playing field etc. should not be lacking.

The second aspect deals with the emotional/social relationship within the school system. This aspect is very important to the achievement of school children. The emotional aspect implies a state of mind that allows the individual to adjust in a satisfactory manner to whatever life has to offer. It encompasses the interactive components of the school system (student-student, teacher-teacher, student-teacher, student-administrative staff 
etc.). This phase of the school health programme offers a good ground for the provision of physical fitness and wellness programme for the school children. The various facilities and equipment that are needed for the prosecution of the fitness and wellness programme are provided for by the implementation of this physical aspect. While the emotional/social aspect takes care of the behavioural aspect of the programmes. For example, good mental health cannot be taught as a subject, but it should permeate the total life of the school system. It means that the school programmes are flexible and geared to individual's needs, a permissive climate prevails, and children are allowed considerable freedom and become self-reliant and other essentials to happy and purposeful living. The use of the school for the aforementioned purposes depends upon adequate and successful interaction of the components of this phase of the school health programme.

\section{Conclusion}

Physical inactivity and negative lifestyles are twin factors that are fighting the enjoyment of vibrant and healthy living in the life of the general populace world over. And the two are deeply rooted in man's behavior begging for modification. The school system has been found to provide a veritable opportunity for behavior moulding and modification. It is on this premise that the school health programme should be saddled with the responsibility of providing for the physical fitness and wellness programme of the school children through its distinct programmes.

It can be therefore concluded that if the school health programme is well planned, organized, funded and supervised, it will provide adequately for the physical fitness and

Wellness programme of the school children.

On the issue of first aid and emergency care, by law, the school acts in loco-parents for the school children. It is therefore assumed that the child will receive the same care and protection during school hours as he/she would receive at home. There could be sudden illness or injury to the children, the school should see to the immediate care through qualified personnel, facilities and supplies.

The third phase of the school health programme is the school healthful living. According to Ogundele (2002), the phase encompasses all the various physical, emotional and social aspect of the school and the measures provided at the school to ensure healthy environment for the school children. This phase is also subdivided into two namely the physical aspect and the emotional/social aspect. The physical aspect has to do with the provision of physical infrastructure and facilities to effect the successful implementation of the first two phases of the programme. Adequate provision of buildings for classrooms, administrative offices, laboratories, health Bay etc, with good ventilation and lighting is very crucial to this phase. Likewise provision of facilities for toilet and waste disposal, food services, playing field etc. should not be lacking.

The second aspect deals with the emotional/social relationship within the school system. This aspect is very important to the achievement of school children. The emotional aspect implies a state of mind that allows the individual to adjust in a satisfactory manner to whatever life has to offer. It encompasses the interactive components of the school system student- student, teacher-teacher, student-teacher, student-administrative staff etc.

This phase of the school health programme offers a good ground for the provision of physical fitness and wellness programme for the school children. The various facilities and equipment that are needed for the prosecution of the fitness and wellness programme are provided for by the implementation of this physical aspect. While the emotional/social aspect takes care of the bahavioural aspect of the programmes. For example, good mental health cannot be taught as a subject, but it should permeate the total life of the school system. It means that the school programmes are flexible and geared to individual needs, a permissive climate prevails, children are allowed considerable freedom and become self-reliant and other essentials to happy and purposeful living. The use of the school for the above stated purposes depends upon adequate and successful interaction of the components of this phase of the school health education programme.

\section{Conclusion}

Physical inactivity and negative lifestyle are twin factors that are fighting the enjoyment of vibrant and healthy living in the life of the general populace world over. And the two are deeply rooted in man's behavior begging for modification. The school system has been found to provide a veritable opportunity for behaviuor moldings and modification. It is on this premise that the school health education should be saddled with the responsibility of providing for the physical fitness and wellness programme of the school children through its distinct programmes.

It can therefore be concluded that if the school health education programme is well planned, organized, funded and supervised, it will provide adequately for the physical fitness and wellness programme of the school children. 


\section{References}

[1] Adegboyega, J.A, Ajayi-Vincent O.B \& Adesina M.O (2005). Essentials of School Health Programme. Ado-Ekiti. Hope and Faith Press Ltd.

[2] Ajayi-Vincent,O.B \&Adesina,M.O (2008). Physical Exercise and Diet:Therapeutic Measures for Good Health and Weight Control. Journal of Nigeria

[3] Association of Sports Science and Medicine (JONASSM) Vol.x, No.2. Hockey, R.V (1993). Physical Fitness, The Pathway of Healthful Living.St. Louis, Mosby Year Inc.

[4] Hoeger, W.K \& Hoeger, S.A (1996). Fitness and Wellness, $3^{\text {rd }}$ ed, Colorado. Morton Publishing Company. Merki, B.M. \& Merki, D. (1987). Health; A Guide to wellness. California Glencoe Publishing Company.

[5] Nwankwo E.I \& Salawu, O.T. (1995). Physical Fitness Status of Female Physical and Health and Non-Physical and Health Education Students. Journals of Nigeria Association of Sports Science and Medicine (JONASSM) Vol. VII.

[6] Ogundele, B.O. (2002). School Health Education Z.A. Ademuwagun, J.A.

[7] Ajala, E.A. Oke, O.A. Moronkola, A.S. Jegede (Eds) Health Education and Health Promotion. Ibadan. Royal People (Nig) Ltd.

[8] Ogwu, N.T. (1995). Health and Fitness through Exercise. Journal of Nigeria Association of Sports Science and Medicine. (JONASSM). Vol. VIII.

[9] Udoh, C.O. (1980). Physical and Health Education, Associate Certificate.Ibadan; Publication Series, Institute of Education, University of Ibadan

[10] Udoh, C.O, Fawole, J.O., Ajala, J.A., Okafor, C \& Nwana O., (1987).Fundamentals of Health Education. Ibadan. Heinemann Educational Books (Nig) Ltd. 